\title{
The Metabolism of Sulphonamides
}

\author{
1. THE METABOLISM OF METANILAMIDE ( $m$-AMINOBENZENESULPHONAMIDE) \\ IN THE RABBIT
}

By F. DOBSON AND R. T. WILLIAMS, Department of Biochemistry, University of Liverpool

(Received 26 October 1945)

The present series of investigations was undertaken with a view to ascertaining whether the metabolic fate of the sulphonamide drugs,. particularly in regard to their oxidation, is in any way related to their antibacterial activity or to their toxic effects.

The first compound selected for study was metanilamide, for preliminary experiments had shown that, in the rabbit, it underwent appreciable oxidation and therefore there was a reasonable chance of isolating its oxidation product in a state of purity. Furthermore, the procedure for the isolation of oxidized metanilamide could serve as a model for the more difficult task of isolating the oxidation product of sulphanilamide. Metanilamide is also a sulphonamide which is easily synthesized.

It may be pertinent at this point to refer briefly to some of the biological properties of metanilamide. To mice it is the least toxic of the three isomeric aminobenzenesulphonamides (Laug \& Morris, 1939; Dyke, 1937). Tréfouel, Tréfouel, Nitti \& Bovet (1937) found it to be therapeutically inactive against streptococcal infections in mice, but in synthetic media devoid of sulphonamide antagonists, Wyss, Strandskov \& Schmelkes (1942) found it capable of inhibiting the respiration of several bacteria as effectively as did sulphanilamide. Sevag, Henry \& Richardson (1943) have shown that, like orthanilamide and sulphanilamide, it inhibits the carboxylase activity of Escherichia coli. Henry (1943) thinks that metanilamide and orthanilamide, despite the fact that they have little or no therapeutic value, may 'have been too hastily regarded as having no fundamental action akin to sulphanilamide'.

No previous study of the fate of metanilamide has been recorded.

\section{METHODS}

Animals. Rabbits, maintained on a constant diet of cabbage and Lever's cubes, were used throughout these experiments.

Ethereal sulphate output was determined according to Williams (1938).

In all experiments in this series of papers, where the , increase in ethereal sulphate output after feeding sulphonamides has been determined, the rabbits used were maintained on a constant diet for at least a week before the feeding of the sulphonamide. In this way the normal output of ethereal sulphate became steady (cf. Williams, 1938). On a diet of $100 \mathrm{~g}$. cabbage $+100 \mathrm{~g}$. Lever's cubes/day, the normal output of ethereal sulphate in the average rabbit (2-3 kg.) is about $20-40 \mathrm{mg}$./day. This diet was used in most experiments. Occasionally a diet of $200 \mathrm{~g}$. cabbage/day was used and here the normal ethereal sulphate output was about $10-30 \mathrm{mg}$./day.

'Free' and 'total' metanilamide were determined in diluted urine (1/50) according to the colorimetric diazo method of Bratton \& Marshall(1939), using $N$-(1-naphthyl)-ethylenediamine hydrochloride (British Drug Houses Ltd.) as the coupling agent, colour measurement being made with a 'Spekker' photoelectric absorptiometer.

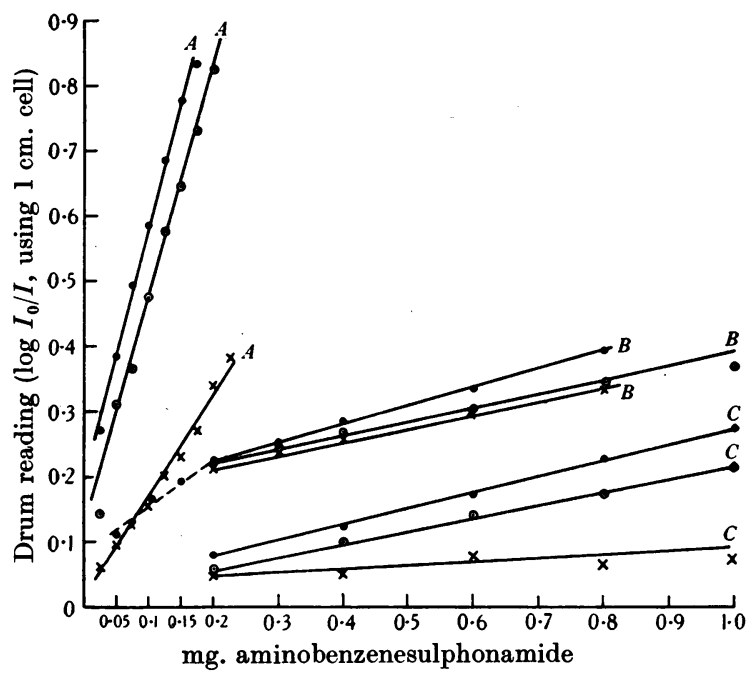

Fig. 1. The relation between drum reading on the 'Spekker' photoelectric absorptiometer and amount of aminobenzenesulphonamide in aqueous solution (using $1 \mathrm{~cm}$. cells and colour filter, Ilford no. 603). $A$ are the curves with $N$-(1-naphthyl)-ethylenediamine as coupling agent. $B$ are the curves with $N$ - $\beta$-sulphatoethyl- $m$-toluidine as coupling agent. $C$ are the curves with dimethyl- $\alpha$-naphthylamine as coupling agent. - sulphanilamide. $\odot-\odot$ metanilamide. $x-\times$ orthanilamide. $\bullet-\bullet$ the common curve for the three sulphonamides in amounts less than $0.2 \mathrm{mg}$., the coupling agent being sulphatoethyltoluidine.

During this part of the work a comparison was made of the relative usefulness of three coupling agents, namely dimethyl- $\alpha$-naphthylamine (Marshall, Emerson \& Cutting, 1937), $N$ - $\beta$-sulphatoethyl- $m$-toluidine (Rose \& Bevan, 1944) and $N$-(l-naphthyl)-ethylenediamine. Fig. 1 shows that the last is the most sensitive and for our purpose it appeared 
to be the most useful for estimating sulphanilamide, metanilamide and orthanilamide in urine. The curves in Fig. 1 were obtained when the total volume of coloured solution was $25 \mathrm{ml}$. with a $1 \mathrm{~cm}$. cell and Ilford colour filter no. 603 (blue-green). It should be noted that in the case of $N$ - $\beta$-sulphatoethyl- $m$-toluidine, the reagent has an increased sensitivity for amounts of all three aminobenzenesulphonamides less than $0.2 \mathrm{mg}$. A further increase in the sensitivity of this reagent could, of course, be achieved if a larger cell $(3 \mathrm{~cm}$.$) had been used.$

Preparation of metanilamide. Metanilamide was prepared either by reduction of $m$-nitrobenzenesulphonamide (from $m$-nitrobenzenesulphonic acid, British Drug Houses Ltd.) in ethanolic $\mathrm{NH}_{4} \mathrm{OH}$ with $\mathrm{H}_{2} \mathrm{~S}$, or from sodium metanilate (British Drug Houses Ltd.) according to Jacobs \& Heidelberger (1917).

\section{RESULTS}

\section{Quantitative determinations}

Ethereal sulphate. The output of ethereal sulphate in rabbits receiving metanilamide is given in Table 1.

Table 1. The excretion of ethereal sulphate after ingestion of metanilamide

\begin{tabular}{|c|c|c|c|c|}
\hline \multirow{2}{*}{$\begin{array}{c}\text { Rabbit } \\
\text { no. }\end{array}$} & \multicolumn{2}{|c|}{ Dose of metanilamide } & \multirow{2}{*}{$\begin{array}{c}\text { Increase in } \\
\text { output of } \\
\text { ethereal } \\
\text { sulphate } \\
\text { (mg. } \mathrm{SO}_{3} / \mathrm{kg} \text {.) }\end{array}$} & \multirow{2}{*}{$\begin{array}{l}\text { Metanil- } \\
\text { amide ex- } \\
\text { creted as } \\
\text { ethereal } \\
\text { sulphate } \\
\text { (\% of dose) }\end{array}$} \\
\hline & (g.) & (mg./kg.) & & \\
\hline 1 & $0 \cdot 769$ & 512 & $53 \cdot 7$ & $23 \cdot 1$ \\
\hline 2 & $0 \cdot 8$ & 49 & 46 & $20 \cdot 1$ \\
\hline 4 & $1 \cdot 119$ & 49 & 45 & $19 \cdot 4$ \\
\hline 2 & $0 \cdot 650$ & 361 & $38 \cdot 0$ & $23 \cdot 3$ \\
\hline
\end{tabular}

In the calculation of the percentage of metanilamide excreted as an ethereal sulphate it is assumed that one molecule of ethereal sulphate is formed from one of metanilamide. The isolation of a monohydroxy- metanilamide (see below) showed this assumption to be correct.

'Free' and 'total' metanilamide. The results are given in Table 2. Some explanation, however, is necessary regarding the meaning of these results.

Table 2. The excretion of 'free' and 'total' metanilamide by the rabbit

\begin{tabular}{|c|c|c|c|c|}
\hline \multirow[b]{2}{*}{$\begin{array}{c}\text { Rabbit } \\
\text { no. }\end{array}$} & \multirow{2}{*}{$\begin{array}{l}\text { Dose of } \\
\text { metanil- } \\
\text { amide } \\
\text { (mg./kg.) }\end{array}$} & \multicolumn{3}{|c|}{$\%$ of dose excreted in 2 days } \\
\hline & & 'Free' & 'Total' & $\begin{array}{l}\text { Apparent } \\
\text { acetylation }\end{array}$ \\
\hline 1 & 250 & 29 & $80 \cdot 5$ & $51 \cdot 5$ \\
\hline 2 & 250 & 47 & 75 & 28 \\
\hline 4 & 250 & 50 & 68 & 18 \\
\hline 8 & 250 & 46 & $81 \cdot 5$ & $35 \cdot 5$ \\
\hline 5 & 100 & 35 & 81 & 46 \\
\hline 45 & 100 & $3 \cdot 5$ & 33 & 30 \\
\hline 46 & 100 & 36 & 68 & 32 \\
\hline 47 & 100 & $14 \cdot 5$ & 90 & $75 \cdot 5$ \\
\hline
\end{tabular}

The term 'free' metanilamide includes all compounds excreted which can be diazotized and coupled with naphthylethylenediamine before acid hydrolysis. These include unchanged metanilamide and the ethereal sulphate and glucuronide of 3 amino-4-hydroxybenzenesulphonamide (4-hydroxymetanilamide) (see Table 3). The amount of free metanilamide excreted must besmall for the material extractable by ether from unacidified- and from acidified-metanilamide urine is mainly acetylmeta nilamide (see below). The glucuronide of 4-hydroxymethanilamide has been described in an earlier paper (Williams, 1943) and in the diazo colour reaction it gives molecule for molecule $70-75 \%$ of the intensity of colour shown by metanilamide.

'Total' metanilamide includes all those compounds which can be diazotized and coupled after

Table 3. Substances reacting with the coupling reagent in the urine from rabbits receiving metanilamide

Before boiling with acid ('free' metanilamide)

$\begin{array}{lc}\text { Compound } & \begin{array}{c}\text { Relative } \\ \text { colour } \\ \text { intensity* } \\ \text { Metanilamide }\end{array} \\ \begin{array}{l}\text { Glucuronide of 4-hydroxymetanil- } \\ \text { amide }\end{array} & 70-75 \\ \begin{array}{c}\text { Ethereal sulphate of 4-hydroxy- } \\ \text { metanilamide } \dagger\end{array} & \begin{array}{c}\text { (Probably } \\ \text { c. 50-70) }\end{array} \\ \text { Colour intensity relative to metanilamide. }\end{array}$

After boiling with acid ('total' metanilamide)

$\overbrace{\begin{array}{c}\text { Compound } \\ \text { Acetylmetanilamide }\end{array}}^{\begin{array}{c}\text { Relative } \\ \text { colour } \\ \text { intensity* }\end{array}}$

Partly hydrolyzed glucuronide Less than of 4-hydroxymetanilamide

$\dagger$ Since this ethereal sulphate, $\mathrm{NH}_{2} \mathrm{SO}_{2} \longrightarrow \mathrm{OSO}_{3} \mathrm{H}$, has not been isolated, its relative colour intensity cannot be given. However, it is likely to give a colour about as intense as the glucuronide. Two compounds containing a strongly acid group ortho to an $\mathrm{NH}_{2}$ group were tested; orthanilic acid, o-sulphonic acid,<smiles>N[Sb](=O)(O[Na])O[Na]</smiles> 
acid hydrolysis of metanilamide urine. These include free metanilamide from acetylmetanilamide, 4-hydroxymetanilamide from the ethereal sulphate, and the partly hydrolyzed glucuronide of 4-hydroxymetanilamide. 4-Hydroxymetanilamide gives only one-tenth of the colour given by an equivalent amount of metanilamide (see Table 3).

The difference between 'free' and 'total' metanilamide does not, therefore, give an exact estimate of the amount of acetylated metanilamide. It should in consequence be pointed out that whenever a sulphonamide undergoes appreciable oxidation in vivo, measurements of total and free sulphonamide by diazotization and coupling do not give the true amount acetylated. In the case of sulphanilamide (see following paper) the amount of oxidation is small and the difference between free and total sulphanilamide is therefore near to the true value for acetylated sulphanilamide.

The urine of rabbits, which have been given metanilamide orally, is 'normal' in appearance, slightly alkaline, non-reducing to Benedict's reagent, gives no colour with ferric chloride, but gives an intense naphthoresorcinol reaction for glucuronic acid and an intense diazo reaction showing the presence of free aromatic amino groups.

\section{Identification of metabolic products}

(a) Isolation of acetylmetanilamide. 1.5 g. metanilamide (m.p. $142^{\circ}$ ) were fed in aqueous suspension to a rabbit $(2 \cdot 2 \mathrm{~kg}$.) by stomach tube. The urine was collected during $24 \mathrm{hr}$., then acidified with dilute $\mathrm{HCl}$ and extracted with ether. The ethereal extract was evaporated and the residue, which gave no diazo reaction, was recrystallized (charcoal) twice from hot water. Crystals were obtained which were identified as $m$-acetaminobenzenesulphonamide, m.p. and mixed m.p. 218-219 (Zincke \& Müller (1913) give m.p. $217^{\circ}$ and Jacobs \& Heidelberger (1917) give m.p. 216-219 ${ }^{\circ}$ ).

In another experiment $16 \mathrm{~g}$. of metanilamide were fed to three rabbits during 3 days. The urine $(2 \cdot 2 \mathrm{l}$. including washings) was collected for 4 days. After centrifuging, the urine, without acidification, was extracted continuously for $54 \mathrm{hr}$. with ether. The ether was evaporated and there remained 6.76 g. of crude acetylmetanilamide (m.p. 175-200 ${ }^{\circ}$. The product gave only a weak diazo reaction, indicating that it contained only small amounts of unchanged metanilamide. The yield of crude acetyl derivative was equivalent to $34 \%$ of the dose.

The extracted urine was now heated on a waterbath for $2 \mathrm{hr}$. to remove dissolved ether, and then boiled gently for $2 \mathrm{hr}$. with $400 \mathrm{ml}$. conc. HCl. After cooling, the product was made just alkaline to litmus with $40 \%(\mathrm{w} / \mathrm{v}) \mathrm{NaOH}$ and then extracted continuously with ether for $25 \mathrm{hr}$. On evaporating the ethereal extract, $4.5 \mathrm{~g}$. of crude metanilamide $(28 \%$ of dose fed) were obtained which contained small amounts of a phenol which is described later. Thus, by ether extraction of the hydrolyzed and unhydrolyzed 'metanilamide' urine, some $62 \%$ of the material fed can be accounted for.

(b) Isolation of 3-amino-4-hydroxybenzenesulphonamide (4-hydroxymetanilamide). Ten rabbits were each given $2 \mathrm{~g}$. metanilamide by stomach tube. The urine $(1840 \mathrm{ml}$. including washings) was collected during 2 days. It was centrifuged and gently boiled with $300 \mathrm{ml}$. conc. $\mathrm{HCl}$ for $2 \mathrm{hr}$., during which time the ethereal sulphate and acetyl derivative, but not the glucuronide, were hydrolyzed. The hydrolyzed mixture was cooled, filtered from some black material and brought to $\mathrm{pH}$ 4-5 with solid $\mathrm{K}_{2} \mathrm{CO}_{3}$. It was then extracted with ether for $50 \mathrm{hr}$. The extracted urine (MA) was kept for examination later. The ethereal extract (MB) was evaporated leaving a brownish crystalline mass containing some brownish syrupy material. The extract which gave an intense red colour with $\mathrm{FeCl}_{3}$ weighed $13 \mathrm{~g}$. or $65 \%$ of the metanilamide fed.

Chromatographic analysis of extract $M B$. The extract, MB, was dissolved in $100 \mathrm{ml}$. hot water, filtered after adding a little charcoal, and cooled. Crystals of metanilamide (5.4 g., m.p. $\left.138^{\circ}\right)$ were filtered off and the filtrate, which gave an intense $\mathrm{FeCl}_{3} \mathrm{re}$ action, was taken to dryness in vacuo. The residue was dissolved in $50 \mathrm{ml}$. absolute ethanol and the solution mixed with $150 \mathrm{ml}$. dry benzene. The mixture was filtered from a very small amount of extraneous material and then poured on to an alumina column (Savory \& Moore's aluminium oxide, standardized according to Brockmann) ( 7 in. long by $1.5 \mathrm{in}$. diameter). The column was eluted with $600 \mathrm{ml}$. $1: 1$ benzene/ethanol, followed by $500 \mathrm{ml}$. absolute ethanol, until the eluates gave a negative diazo reaction. Up to this point none of the eluates had given a colour with $\mathrm{FeCl}_{3}$, although the column had been washed free of metanilamide. The combined eluates were evaporated and yielded $3 \cdot 75 \mathrm{~g}$. of metanilamide, m.p. $142-3^{\circ}$, after recrystallization from water.

The alumina column at this point showed three distinct zones, a lower zone devoid of colour, a central yellow zone and an upper light brown zone. The column was, therefore, cut into three parts and each zone, $t$ (top), $m$ (middle) and $b$ (bottom), was extracted with boiling water. Aqueous extracts of zones $m$ and $t$ were alkaline to litmus. Zone $m$ yielded $1.5 \mathrm{~g}$. of solid material after evaporation of the solvent, and zone $t$ yielded $0.95 \mathrm{~g}$. of solid. The reaction with $\mathrm{FeCl}_{3}$ of both zones $m$ and $t$ was purplish red $\rightarrow$ red $\rightarrow$ brown. Zone $b$ yielded nothing.

The solid from zone $m$ was recrystallized (charcoal) from $15 \mathrm{ml}$. acidulated water and $0.45 \mathrm{~g}$. of slightly brown elongated platelets obtained. The crystals had m.p. 200-201 ${ }^{\circ}$ and mixed m.p. 201-202 ${ }^{\circ}$ with 
authentic 3-amino-4-hydroxybenzenesulphonamide, m.p. $202^{\circ}$ (Williams, 1943; Kermack, Spragg \& Tebrich, 1939). (Found: C, 38.3; H, 4.4; N, 15.3; S, $17 \cdot 2 \%$. Calc. for $\mathrm{C}_{6} \mathrm{H}_{8} \mathrm{~N}_{2} \mathrm{O}_{3} \mathrm{~S}: \mathrm{C}, 38 \cdot 3 ; \mathrm{H}, 4 \cdot 3$; $\mathrm{N}, 14.9 ; \mathrm{S}, 17.0 \%$.) They gave with $\mathrm{FeCl}_{3}$ solution a purplish red colour which quickly turned red, then brown with final deposition of a brown precipitate; on diazotization with nitrous acid they gave a deep yellow solution which slowly coupled with ethanolic dimethyl- $\alpha$-naphthylamine giving a dark-red coloration. These reactions are identical with those given by 3-amino-4-hydroxybenzenesulphonamide (4-hydroxymetanilamide) and establish the identity of the phenol from zone $m$.

The solid from zone $t$ also contained the above phenol as indicated by colour reactions although it was not obtained crystalline. The solid extract from zone $t$ was dissolved in $10 \mathrm{ml}$. hot acidulated water (charcoal) and filtered. On cooling no crystals appeared, but on further acidification small colourless plates $(0 \cdot 1$ g. $)$, m.p. $119^{\circ}$, separated. These were identified as benzoic acid by a mixed melting-point $\left(119-120^{\circ}\right)$ with authentic benzoic acid. This acid is, of course, derived from hippuric acid which is a normal constituent of rabbit urine.

\section{DISCUSSION}

Metanilamide undergoes in the rabbit both acetylation and oxidation. Little free metanilamide appears to be excreted, for in two experiments only acetylmetanilamide could be extracted from the urine with ether despite the fact that free metanilamide is easily extractable by ether. The amount of metanilamide acetylated is uncertain. The differences between the 'free' and 'total' metanilamide (apparent acetylation) given in Table 2, yield figures for acetylated metanilamide varying from 18 to $75 \%$ of the dose. The uncertainty of these values has already been discussed. By direct ether extraction of urine for $54 \mathrm{hr}$. some $34 \%$ of the metanilamide fed can be obtained as acetylmetanilamide, but, on hydrolysis of the extracted urine, a further $28 \%$ of the dose is extractable by ether as free metanilamide. This $28 \%$ must have been derived from unextracted acetylmetanilamide, indicating that up to $62 \%$ of the metanilamide is excreted acetylated. Although these two ways of assessing the amount of metanilamide undergoing acetylation in the body do not give exact results they indicate that metanilamide undergoes appreciable acetylation in the rabbit and that probably about one-half of the dose is excreted acetylated.

If both the ethereal sulphate and glucuronide outputs of metanilamide-fed rabbits could be estimated, then an exact estimation of the extent of oxidation of metanilamide could be obtained. Only the ethereal sulphate output could be estimated with any degree of accuracy and the sulphate estimations indicated that some $20-25 \%$ of metanilamide is oxidized to a phenol, which is excreted conjugated as an ethereal sulphate. Since the oxidation product of metanilamide is 4-hydroxymetanilamide it is likely that the glucuronide excreted is 4-glucuronosidometanilamide (see Williams, 1943). Such a glucuronide is fairly resistant to acid hydrolysis (cf. Hanson, Mills \& Williams, 1944) and its estimation by the naphthoresorcinol-HCl method is unsatisfactory.

4-Hydroxymetanilamide could be formed from metanilamide in three ways, thus:

(1) by direct oxidation,

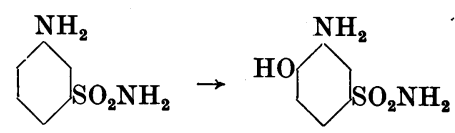

(2) by direct oxidation of the acetyl derivative,

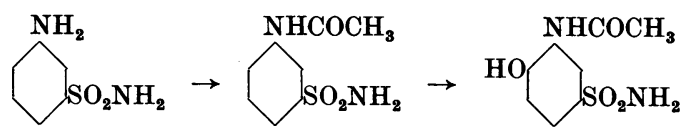

(3) by rearrangement of a hydroxylamine,

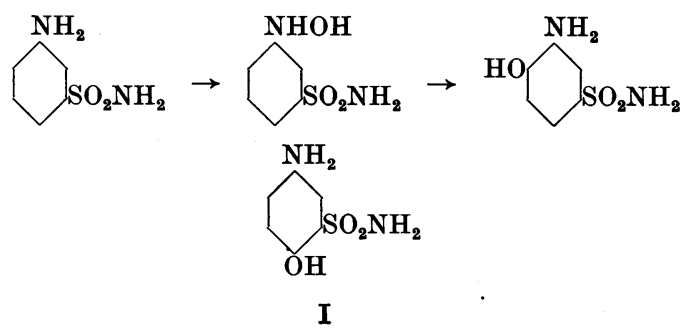

No evidence was obtained during this work that a hydroxylamine was formed, and if it were formed the presence of a $p$-aminophenol, i.e. 6-hydroxymetanilamide (I), could also be expected. Such a phenol was not detected (the glucuronide of 6-hydroxymetanilamide has been prepared by Williams, 1943).

Regarding mechanisms (1) and (2) it appears that the first is likely to be the correct one. Examination of Table 2 shows that about $30-50 \%$ of the metanilamide fed is excreted in a form which diazotizes and couples with naphthylethylenediamine, yet very little free metanilamide can be extracted from the urine with ether. These facts lead to the conclusion that the 'free' metanilamide estimated by the diazo method is mainly the ethereal sulphate and glucuronide of 4-hydroxymetanilamide in which the amino group is free (see Table 3). This suggests that the ethereal sulphate excreted is that of 4-hydroxymetanilamide and not of 4-hydroxy-3-acetylmetanilamide. 


\section{SUMMARY}

The fate of metanilamide in the rabbit has been studied.

1. This compound is converted in vivo into $m$-acetaminobenzenesulphonamide and the ethereal sulphate and glucuronide of 4-hydroxymetanilamide.
2. About $50 \%$ is acetylated and more than $25 \%$ is oxidized to 4-hydroxymetanilamide.

3. $20-25 \%$ of the metanilamide is excreted as an ethereal sulphate.

The expenses of this work were defrayed by a grant from the Medical Research Council.

\title{
REFERENCES
}

Bratton, A. C. \& Marshall, E. K. (1939). J. biol. Chem. 128, 537.

Dyke, W. J. C. (1937). Quart. J. Pharm. 10, 319.

Hanson, S. W. F., Mills, G. T. \& Williams, R. T. (1944). Biochem. J. 38, 274.

Henry, R. J. (1943). Bact. Rev. 7, 204.

Jacobs, W. A. \& Heidelberger, M. (1917). J. Amer. chem. Soc. 39, 2428.

Kermack, W. O., Spragg, W. T. \& Tebrich, W. (1939). J. chem. Soc. p. 608.

Laug, E. P. \& Morris, H. J. (1939). Proc. Soc. exp. Biol., N.Y., 42, 541 .
Marshall, E. K., Emerson, K. \& Cutting, W. C. (1937). J. Amer. med. Ass. 108, 953.

Rose, F. L. \& Bevan, H. G. L. (1944). Biochem. J. 38, 116.

Sevag, M. G., Henry, J. \& Richardson, R. (1943). Amer. J. Med. Sci. 205, 877.

Tréfouel, J., Tréfouel, Mme., Nitti, F. \& Bovet, D. (1937). Ann. Inst. Pasteur, 58, 39.

Williams, R. T. (1938). Biochem. J. 32, 878.

Williams, R. T. (1943). Biochem. J. 37, 329.

Wyss, O., Strandskov, F. B. \& Schmelkes, F. C. (1942). Science, 96, 236.

Zincke, T. \& Müller, J. (1913). Ber.dtsch. chem. Ges. 46, 777.

\section{The Metabolism of Sulphonamides}

\section{THE ISOLATION AND IDENTIFICATION OF 3-HYDROXYSULPHANILAMIDE AS THE OXIDATION PRODUCT OF SULPHANILAMIDE IN THE RABBIT}

\author{
By R. T. WILLIAMS, Department of Biochemistry, University of Liverpool
}

(Received 26 October 1945)

Although it is known that a number of the sulphonamide drugs used in therapy undergo oxidation in vivo, none of the oxidation products have hitherto been chemically identified. Scudi (1940) isolated from the urine of dogs receiving sulphapyridine a monohydroxysulphapyridine, m.p. $180-181^{\circ}$, but left its structure undetermined. Weber, Lalich \& Major (1943) isolated from dog's urine a glucuronide of a hydroxysulphapyridine in which the hydroxyl group is attached to the pyridine ring. No other data of this type has been published on sulphonamide oxidation products.

The determination of the exact chemical nature and the biological properties of sulphonamide oxidation products is highly important since certain theories relative to the mode of action of sulphonamide drugs involve the formation of oxidation products. Mayer \& Oechslin (1937) suggested that the activity of sulphanilamide was due to its conversion in vivo to an oxidation product which they suggested might be $p$-hydroxylaminobenzenesulphonamide ( $N^{4}$-hydroxysulphanilamide), this being the effective therapeutic agent. Another theory involving the hydroxylamine derivative was put forward by Locke, Main \& Mellon (1938), who assumed that since hydroxylamine $\left(\mathrm{NH}_{2} \mathrm{OH}\right)$ and oximes inhibit catalase, $p$-hydroxylaminobenzenesulphonamide would do the same (this is actually true; see Sevag, Shelburne \& Ibsen (1942)). Hydrogen peroxide, normally resulting from the metabolic activities of bacteria such as streptococci and pneumococci, would not be removed by catalase if $p$-hydroxylaminobenzenesulphonamide were present and would therefore accumulate, and in turn destroy the bacteria. Some workers (e.g. Rosenthal \& Bauer, 1939; James, 1940) claimed to have detected hydroxylamine derivatives in the urine of patients and of animals receiving sulphanilamide, but these claims were shown to be invalid by Thorpe, Williams \& Shelswell (1941). In all, some four compounds have been suggested as oxidation products of sulphanilamide, i.e. $N^{4}$-hydroxy- (I), 3-hydroxy(II) and 2-hydroxysulphanilamide (III) and $p$ aminophenol (IV) (cf. James, 1940; Thorpe et al. 